\title{
Small-scale nutrient patches in tidally mixed coastal waters
}

\author{
Laurent Seuront ${ }^{1, *}$, Valérie Gentilhomme ${ }^{2}$, Yvan Lagadeuc ${ }^{3}$ \\ ${ }^{1}$ Department of Ocean Sciences, Tokyo University of Fisheries, 4-5-7 Konan, Minato-ku, Tokyo 108-8477, Japan \\ ${ }^{2}$ Ecosystem Complexity Research Group, Station Marine de Wimereux, UMR 8013 ELICO, \\ Université des Sciences et Technologies de Lille, BP 80, 62930 Wimereux, France \\ ${ }^{3}$ Université de Caen, Laboratoire de Biologie et Biotechnologies Marines, IUT Génie Biologique, Bd du Maréchal Juin, \\ 14032 Caen cedex, France
}

\begin{abstract}
In the eastern English Channel, characterized by its megatidal regime and the resulting very high turbulence, phytoplankton biomass and purely passive scalars such as temperature and salinity are basically regarded as homogenised by turbulent fluid motions. However, recent studies have demonstrated - on the basis of innovative statistical analyses in marine ecology - that these parameters were heterogeneously distributed at a small scale. We extend these concepts to highresolution time series of dissolved nitrogen $\left(\mathrm{NO}_{2}{ }^{-}\right)$. We first demonstrate the validity of our sampling procedure of continuously measuring nitrite concentration (3 s temporal resolution). Second, we describe how these time series recorded at different times of 4 tidal cycles can be characterized as heterogeneously distributed using fractal and multifractal parameters, and then can be described in terms of small-scale patches. In addition, we show how multifractal parameters can be regarded as being both qualitatively and quantitatively more informative than a single fractal dimension. These parameters showed very specific temporal patterns revealing the absence of density-dependence of nitrite distribution. In contrast, nitrite distributions clearly appeared to be less heterogeneously distributed under higher turbulence, suggesting a physical control of small-scale nutrient patchiness. Nevertheless, taking into account the different structures of nitrite distributions under high and low turbulence, we suggest that the observed small-scale nutrient patches could be the result of complex interactions between hydrodynamic conditions, biological processes related to phytoplankton populations, and the productive efficiency of bacterial populations. This hypothesis is supported by observations that the structure of temperature and salinity - regarded as passive scalars under purely physical control of turbulent motions - recorded simultaneously to the nitrite data remained similar under all hydrodynamic conditions.
\end{abstract}

KEY WORDS: Turbulence $\cdot$ Patchiness $\cdot$ Nitrite $\cdot$ Time series $\cdot$ Tidal forcing $\cdot$ Fractal and multifractal analysis

\section{INTRODUCTION}

The ecological importance of space-time heterogeneity in phytoplankton populations has been pointed out by several authors (e.g. Hutchinson 1961, Margalef 1967, Platt 1975) and widely investigated both in marine and

${ }^{*}$ Present address: Ecosystem Complexity Research Group, Station Marine de Wimereux, UMR 8013 ELICO, Université des Sciences et Technologies de Lille, BP 80, 62930

Wimereux, France. E-mail: laurent.seuront@univ-lille1.fr

() Inter-Research $2002 \cdot$ www.int-res.com freshwater ecology (e.g. Platt 1972, Powell et al. 1975, Abbott et al. 1982, Weber et al. 1986, Denman \& Abbott 1994). However, in spite of the intensive investigations conducted on the nutrient dependence of phytoplankton growth (Jickells 1998, McCarthy et al. 1998) that provided direct evidence for nutrient control of photosynthesis in the ocean (Platt et al. 1992, Falkowski et al. 1998), studies concerning the small-scale heterogeneity of nutrients are still scarce (Estrada \& Wagensberg 1977, Steele \& Henderson 1979). 
The small-scale distribution of nutrients in the sea is nevertheless a particular salient issue in marine ecology. Indeed, if small-scale heterogeneity in the distribution of nutrients is really more prevalent than generally thought, for instance, new production by phytoplankton might have been biased in many environments, especially at the continental margins of the ocean, where spatio-temporal variability of both physical and biological processes is usually very developed (see e.g. Mackas et al. 1985, and references therein). Indeed, while some studies have been dedicated to spatio-temporal distributions of phyto- and zooplankton (Brylinski et al. 1984, 1988, Brunet et al. 1993, Seuront et al. 1996a,b, 1999, Seuront \& Lagadeuc 1998), results concerning the spatio-temporal distribution of nutrients are still scarce in this area (Bentley et al. 1993, Gentilhomme \& Lizon 1998), especially on smaller scales.

In the eastern English Channel and the Southern Bight of the North Sea, characterized by their megatidal regime and the resulting very high turbulence, recent studies have shown that phytoplankton biomass is neither randomly nor homogeneously distributed but rather exhibits a very structured small-scale patchy distribution similar to that of purely passive scalars such as temperature and salinity (Seuront et al. 1996a,b, 1999). The question is then to know whether dissolved nitrogen exhibits a structured distribution driven purely by physical forces (i.e. similar to that observed regarding temperature and salinity) or another kind of distribution, suggesting another level of complexity in the structure of nutrient variability.

However, studies of small-scale distributions are subject to both technical and statistical limitations. Small-scale patches with elevated nitrogen content cannot be observed with present-day techniques. The fastest response nutrient analyser allows, to our knowledge, only a 2 min temporal resolution (Sakamoto et al. 1996) and is still insufficient to work in the coastal ocean, where spatio-temporal variability is high relative to the open ocean (Mackas et al. 1985). Previous statistical studies of plankton patchiness, mainly based on spectral analysis (see e.g. Platt \& Denman 1975, Fasham 1978), have allowed inferences on when biological processes contribute significantly to phytoplankton spatial structure, over spatial scales ranging from tens of meters to tens of kilometers. However, while able to quantify the variance as a function of scales, these techniques, based on second order statistics and Gaussian hypotheses, were not able to reveal the precise variability associated with those scales and the mechanism of the physical-biological interactions, particularly at small scales (i.e. meters and seconds). This is in the range where physical forces dominate biological processes (e.g. Seuront et al. 1996a,b, 1999). Herein, the goal of this paper is: (1) to demonstrate the validity of a high resolution (i.e. a $3 \mathrm{~s}$ temporal resolution) dissolved nitrogen analysis technique; (2) to show how high resolution nitrogen time series can be wholly characterized in terms of structured variability in the powerful framework of multifractal analyses in a more efficient way than in a spectral framework; and (3) to reveal how the organization of this structured variability can be regarded as mainly dependent on hydrodynamic conditions.

\section{MATERIALS AND METHODS}

Sampling experiment. Sampling was conducted during $48 \mathrm{~h}$ (ca 4 tidal cycles) in a period of spring tide, from 2 to 4 April 1996, at an anchor station (Fig. 1) located in the coastal waters (i.e. the 'Coastal Flow'; Brylinski et al. 1991) of the eastern English Channel $\left(50^{\circ} 47^{\prime} 300^{\prime \prime} \mathrm{N}, 1^{\circ} 33^{\prime} 500^{\prime \prime} \mathrm{E}\right)$. Measurements of physical parameters (temperature and salinity) and in vivo

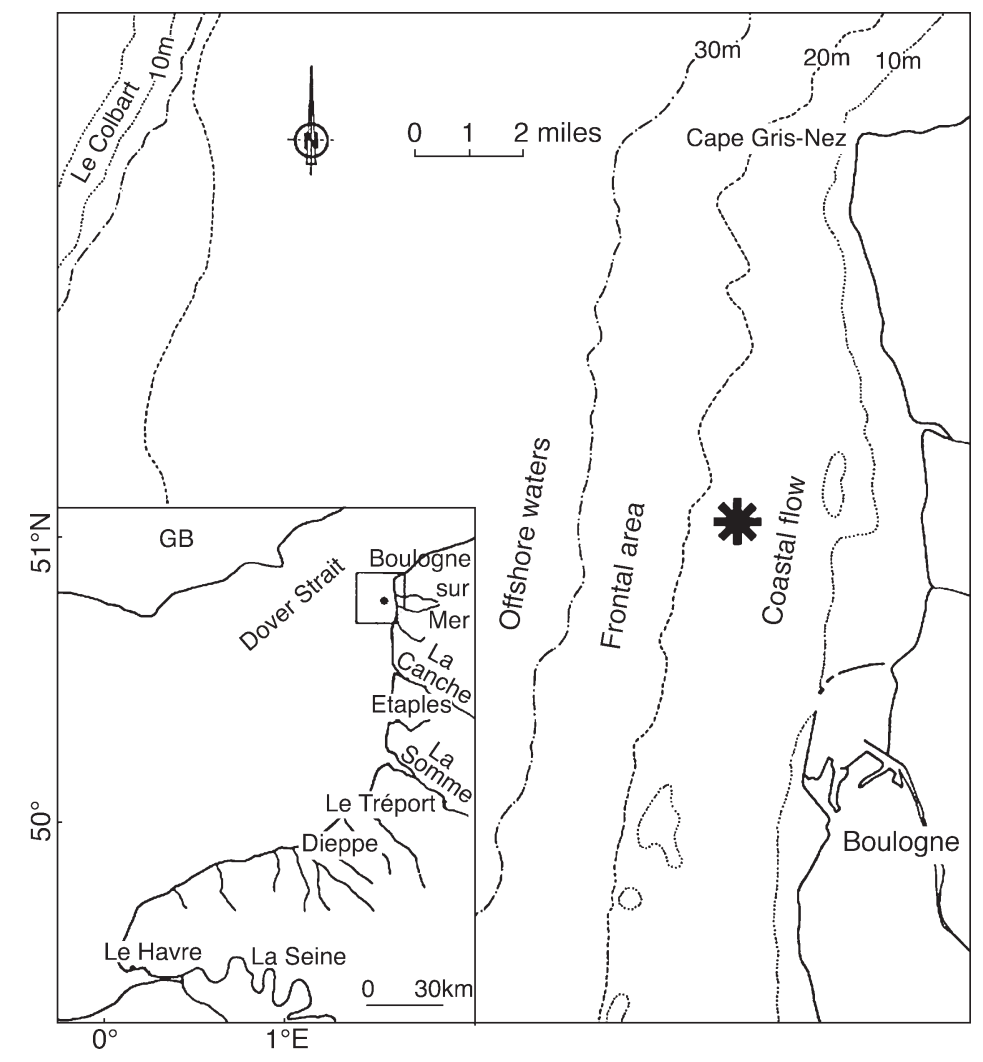

Fig. 1. Study area and location of the sampling station (*) along the French coast of the eastern English Channel 
fluorescence were taken every hour from the surface to the bottom with an SBE 19 Sealogger CTD and a Sea Tech fluorometer, respectively. Every $5 \mathrm{~min}$, current speed and direction were measured at 3,6 and $10 \mathrm{~m}$ with Anderra current meters. Every hour, wind data were collected with the on-board anemometer. Every 2 $\mathrm{h}$, water samples were taken at 2, 6, 10 and $16 \mathrm{~m}$, using Niskin bottles. Dissolved inorganic nitrogen concentrations (5 $\mathrm{ml}$ frozen samples, analysed using a Technicon autoanalyzer II; Treguer \& Le Corre 1971) and chl a concentrations (1 l filtered frozen samples, extracted with $90 \%$ acetone, assayed in a spectrophotometer and the chl a concentration calculated following Strickland \& Parsons 1972) were estimated for each sampled depth.

High-resolution nitrogen sampling design. We focused on nitrite $\left(\mathrm{NO}_{2}{ }^{-}\right)$rather than nitrate $\left(\mathrm{NO}_{3}{ }^{-}\right)$or ammonium $\left(\mathrm{NH}_{4}{ }^{+}\right)$concentration for both conceptual and technical reasons. Nitrite is indeed the most conservative nutrient and can be expected to behave as a purely passive scalar. Therefore the observed variability will presumably be little or not biased by biological processes such as phytoplankton uptake and release as nitrate and ammonium can be. Moreover, nitrite allows a higher temporal resolution than nitrate - and then more direct comparisons with the $0.5 \mathrm{~s}$ resolution reached by Seuront et al. (1996a,b, 1999) - because of the substantial smoothing introduced by the reduction process associated with nitrate determination (see Treguer \& Le Corre 1971 for further details).

In order to continuously investigate the small-scale distribution of nitrite $\left(\mathrm{NO}_{2}^{-}\right)$, water was continuously taken from a depth of $0.25 \mathrm{~m}$ through a sea-water intake mounted on a suspended hose at a distance of $1 \mathrm{~m}$ away from the hull of the vessel, and directly processed in a Technicon autoanalyzer II (Treguer \& Le Corre 1971) by means of a railwheel pump connected to $1.5 \mathrm{~mm}$ diameter plastic tubing (Fig. 2) with an

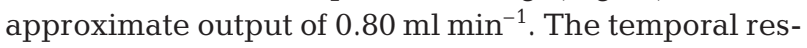
olution (i.e. $3 \mathrm{~s}$ ) was chosen as the minimum time interval allowed by the Technicon autoanalyzer II between 2 nitrite quantity determinations. One may note here that such an approach, while suggested by Treguer \& Le Corre (1971) has, to our knowledge, never been used in that way except by Estrada \& Wagensberg (1977) with a lower temporal resolution (1 $\mathrm{min}$ ) and a considerable smoothing of the output signal associated with the dimension of the pumping apparatus.

In more practical terms, the Reynolds number associated with our pumping apparatus was low (i.e. Re 18.75) and indicated that no turbulent processes occurred during the pumping in the plastic tubing. We then subsequently estimated the characteristic length scale, $L$, covered by the nitrite molecules because of molecular diffusion occurring in the plastic tubing dur- ing pumping following $L=\sqrt{(D \times t)}$ (Mann \& Lazier 1991), where $D$ is the molecular diffusion $\left(D=10^{-9} \mathrm{~m}^{2}\right.$ $\mathrm{s}^{-1}$ ) and $t$ the diffusion time scale (i.e. the time taken by the water to be brought through the Technicon autoanalyzer II; $t=20 \mathrm{~min}$ ). This led to a characteristic diffusion length scale $L=10^{-3} \mathrm{~m}$ which is about 5 orders of magnitude lower than the intersample bubbling used by the Technicon autoanalyzer II. We can state that our pumping apparatus cannot be responsible for any biasing associating with turbulent or molecular diffusion.

Finally, our sampling cannot be biased by the boundary layer occurring around the hull of the vessel because of the $1 \mathrm{~m}$ distance chosen for our seawater intake. Indeed, the thickness of a boundary layer, $\delta$, increases with increasing distance from the leading edge according to $\delta=(x \vee / u)^{1 / 2}$ (Mann \& Lazier 1991), where $x(m)$ is the distance from the leading edge (i.e. the distance from the ship bow) where water has been continuously taken (i.e. $x=15 \mathrm{~m}), v$ the kinematic viscosity $\left(10^{-6} \mathrm{~m}^{2} \mathrm{~s}^{-1}\right)$ and $u\left(\mathrm{~m} \mathrm{~s}^{-1}\right)$ the free-stream velocity. We then estimated $\delta$ for the range of free-stream velocities (i.e. 0.10 to $1.04 \mathrm{~m} \mathrm{~s}^{-1}$ ) experienced during the sea water pumping experiment as being in the range 0.38 to $1.22 \mathrm{~cm}$. The potential influence of such a minute boundary layer thickness in the temporal patterns on the nitrite measurements can then be neglected in the present case.

We then recorded 11 time series of nitrite concentrations of approximately $1 \mathrm{~h}$ duration at a sampling frequency of $0.33 \mathrm{~Hz}$; data were directly recorded on a PC

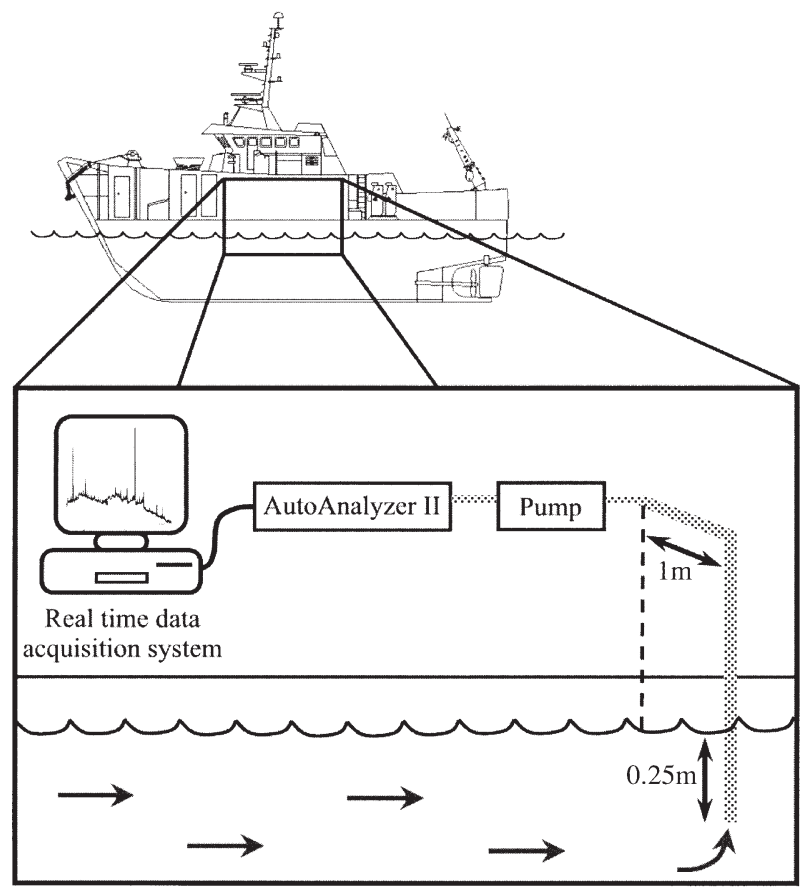

Fig. 2. Side view schematic diagram of the experimental setup used to continuously sample subsurface water 
by means of a data logger system interfaced with the Technicon autoanalyzer II. Between each time series, the whole plastic tubing was rinsed with $\mathrm{HCl} 10 \%$, Milli-Q water and the Technicon autoanalyzer II was calibrated using a standardized nitrogen solution. In order to allow comparisons between nitrite time series and the structure of passive scalars under purely physical control of turbulent motions, we recorded temperature and salinity with an SBE 25 Sealogger CTD simultaneously to the 11 nitrite time series sampling and at a roughly similar sampling resolution $(0.5 \mathrm{~Hz})$.

Data analysis. The dynamic stability of the water column was calculated using the total shear squared (Lizon et al. 1995):

$$
S^{2}=(\Delta u / \Delta z)^{2}+(\Delta v / \Delta z)^{2}
$$

where $\Delta z$ is depth variation; $\Delta u$ and $\Delta v$ are variations in the speed of the 2 orthogonal components $u$ (crosschannel) and $v$ (along-channel). The vertical stability of the water column cannot be estimated by the Richardson number $(R i)$ or static stability $\left(N^{2}\right)$ when there is no vertical gradient of density.

The dissipation rate of turbulent energy induced by tide $\varepsilon_{t}\left(\mathrm{~m}^{2} \mathrm{~s}^{-3}\right)$ was calculated following MacKenzie \& Leggett (1993):

$$
\varepsilon_{t}=\phi u^{3} / h
$$

where $\phi, u$ and $h$ are the fraction of the tidal energy which is used for vertical mixing $(\phi=0.006$, Bowers \& Simpson 1987), the $M_{2}$ depth-averaged tidal velocity $\left(\mathrm{m} \mathrm{s}^{-1}\right)$ and the water column height $(\mathrm{m})$, respectively. Values of $\varepsilon_{t}$ exceeding $2.4 \times 10^{-5} \mathrm{~m}^{2} \mathrm{~s}^{-3}$ (i.e. values of $\left.u^{3} / h\right)>0.004 \mathrm{~m}^{2} \mathrm{~s}^{-3}$ ) are typical of tidally mixed areas (MacKenzie \& Leggett 1991).

The effect of wind events being of main interest in structuring the whole water column (Raby et al. 1994, Lagadeuc et al. 1997, Seuront \& Lagadeuc 1997), we especially focused on the relative effects of dissipation rates of turbulent energy induced by wind on the subsurface small-scale distribution of nitrite. Thus, we estimated the dissipation rates of wind-generated turbulent kinetic energy $\varepsilon_{W}\left(\mathrm{~m}^{2} \mathrm{~s}^{-3}\right)$ using the formulation of the boundary layer model used by MacKenzie \& Leggett (1991) as:

$$
\varepsilon_{W}=\left(5.82 \times 10^{-9}\right) W^{3} / z
$$

where $W$ and $z$ are the wind speed $\left(\mathrm{m} \mathrm{s}^{-1}\right)$ and the sampling depth $(\mathrm{m})$, respectively.

Fractal and multifractal analyses. In this study we have used 2 related but conceptually different analysis methods to investigate the temporal structure of nitrite concentrations. The first method is based on a 1dimensional fractal approach, thus assuming that the process can be described by a single fractal dimension, $D$ (Mandelbrot 1977, 1983). Under this assumption, when all or parts of a power spectrum $E(f)$ obeys a power-law form:

$$
E(f) \approx f^{-\beta}
$$

where $f$ is frequency, this indicates the absence of a characteristic time-scale in the range of the power law, i.e. a scaling behaviour. The power law form will manifest itself as an approximately straight-lined behaviour of the power spectrum when plotted in a doublelogarithmic diagram. For time series, the exponent $\beta$ and the fractal dimension $D$ are related according to (Schroeder 1991):

$$
D=d+1-(\beta-1) / 2
$$

where $d$ is the Euclidean dimension of the observation space ( $d=1$ for time series). For time series, the fractal dimension $D$ takes values between 1 and 2 . A low $D$ value means that the heterogeneity is high (strong autocorrelation) and there may be dominant long-range effects, while a high $D$ value indicates that the variable is randomly distributed in time (weak or no autocorrelation) and that only weak short-range effects exit (see e.g. Seuront \& Lagadeuc [1997] for further details).

The second method, which is based on the so-called structure functions (i.e. a high order statistical generalization in the real domain of the power spectrum), has been extensively described and illustrated elsewhere (Seuront et al. 1999) and we will only review its main properties here. For a time series of a given quantity $Q$, $q^{\text {th }}$ order structure functions can be defined as:

$$
<(\Delta Q(\tau))^{q}>=\left\langle|Q(t+\tau)-Q(t)|^{q}>\right.
$$

where $\langle\ldots\rangle$ indicates statistical averaging and $<(\Delta Q(\tau))^{q}>$ is the $q^{\text {th }}$ order statistical moments of the fluctuations of the quantity $Q$ at scale $\tau$. For scaling processes, the scale invariant structure function exponents $\zeta(q)$ which characterize all the statistics of the field are defined as:

$$
<(\Delta Q(\tau))^{q}>\approx \tau^{\zeta(q)}
$$

The scaling exponents $\zeta(q)$ are estimated by the slope of the linear trends of $\left\langle(\Delta Q(\tau))^{q}>\right.$ vs $\tau$ in a log-log plot. The first moment gives the scaling exponent $H=$ $\zeta(1)$ corresponding to the scale dependency of the average absolute fluctuations: indeed, if $H \neq 0$ the latter will depend on the time scale $\tau_{\text {; }}$ it therefore characterizes the degree of non-conservation of the process. For simple scaling (monofractal) processes, the function $\zeta(q)$ is linear. For multifractal processes, this function is non-linear and concave (Seuront et al. 1999).

It can be noticed that the function $\zeta(q)$ could depend on a very large number of parameters (a priori an infinite number of non-integer values of $q$ ). However, in the framework of universal multifractals, $\zeta(q)$ can be determined by only 3 parameters as: 


$$
\zeta(q)=q H-\frac{C_{1}}{\alpha-1}\left(q^{\alpha}-q\right)
$$

$C_{1}$ is the codimension that characterizes the sparseness (i.e. heterogeneity) of the process, and satisfies $0 \leq C_{1}$ $\leq d$ ( $d$ is the Euclidean dimension of the observation space): $C_{1}=0$ for a homogeneous process and $C_{1}$ is higher as the process is sparse, indicating that the field values corresponding to any given level of variability are more infrequent. The Lévy index $\alpha$ is the degree of multifractality, bounded between $\alpha=0$ and $\alpha=2$ corresponding to the extreme monofractal and log-normal multifractal cases, respectively. In other words, the second term of Eq. (8) expresses the multifractal deviation from monofractality, in which case $\zeta(q)=q H$. The distance between monofractality and multifractality is then a function of $\alpha$ and $C_{1}$. The knowledge of these parameters suffices to characterize all the statistics of the field. $C_{1}$ is given by:

$$
\zeta^{\prime}(1)=H-C_{1}
$$

and $\alpha$ is estimated as the best non-linear fit of Eq. (8), for values between 0 and 2, using a simplex procedure (O'Neill 1971).

An objective criterion is needed to decide upon an appropriate range of scales to include in the regressions to determine both the spectral exponents $\beta$ and the structure function scaling exponents $\zeta(q)$. We used the values of the frequencies and the time scales which maximised the coefficient of determination $\left(r^{2}\right)$ and minimised the total sum of the squared residuals for the regression (Seuront \& Lagadeuc 1997). Before performing the calculations, the measured time series must be detrended and normalized. This is done, first, by calculating Kendall's coefficient of rank correlation, $\tau$, between time series and the $x$-axis values in order to detect the presence of a linear trend (Kendall \& Stuart 1966). Then, if required, the time series is detrended by fitting linear regressions to the original data by least squares and by using the regression residuals in further analysis, a common remedial procedure in timeseries analysis equivalent to high-pass filtering (Fuller 1976). Second, the measured time series were normalised (non-dimensionalised) by dividing all values by the average over the total series.

\section{RESULTS}

\section{Environmental conditions}

The values of the vertical shear activity, $S^{2}(0.0005 \pm$ $\left.0.0004 \mathrm{~s}^{-1} \mathrm{SD}\right)$, which can generate turbulence were always greater than $2.4 \times 10^{-4} \mathrm{~s}^{-1}$, a low shear effect according to Itsweire et al. (1989), indicating an ele- vated shear activity in the whole water column. At all depths, current vectors showed wide variations, which were related to the semidiurnal M2 (12.4 h) tidal component. It resulted in variations of $6 \mathrm{~h}$ periodicity in the current speed, which ranged from 5 to $116 \mathrm{~cm} \mathrm{~s}^{-1}$ at $3 \mathrm{~m}$ depth. A moderate NNE wind $\left(4.4 \pm 0.2 \mathrm{~m} \mathrm{~s}^{-1}\right)$ blew during the whole sampling experiment, leading to a dissipation rate of $5.24 \times 10^{-7} \mathrm{~m}^{2} \mathrm{~s}^{-3}$ at $1 \mathrm{~m}$ depth. Moreover, the depth-averaged mean dissipation rate of tidally induced turbulent energy, $\varepsilon_{t}\left(\varepsilon_{t}=6.85 \times 10^{-5}\right.$ $\mathrm{m}^{2} \mathrm{~s}^{-3}$ ), significantly higher than the wind-generated turbulent dissipation rate $\varepsilon_{t}\left(\varepsilon_{t}=5.24 \times 10^{-7} \mathrm{~m}^{2} \mathrm{~s}^{-3}\right.$ at $1 \mathrm{~m}$ depth), characterizes a tidally mixed area and indicates a negligible effect of wind-induced turbulent kinetic energy on the water column. Autocorrelation of salinity, and cross-correlation between current direction and salinity, show that this parameter also varied with a periodicity of $12 \mathrm{~h}$, and was negatively correlated with current direction. Temperature exhibits a slightly complex behaviour, showing a light-dark cycle (sinusoidal regression, $r^{2}=0.68$ ) superimposed on a significantly autocorrelated $(\mathrm{p}<0.05) 12 \mathrm{~h}$ tidal cycle. In all cases, the water column always has no vertical structure.

\section{Nutrients and phytoplankton biomass}

The mean nitrite and nitrate concentrations were $0.17 \pm 0.02$ and $0.71 \pm 0.14 \mathrm{mmol} \mathrm{l}^{-1}$, respectively, while mean chl a concentration was $17.91 \pm 1.10 \mu \mathrm{g} \mathrm{l^{-1 }}$. There was a significant $12 \mathrm{~h}$ tidal cycle in nutrient and chl a concentrations, and no statistical differences between mean values at the 4 sampled depths, as shown by autocorrelation analyses $(\mathrm{p}<0.05)$ and Kruskal-Wallis test $(\mathrm{p}<0.05)$, respectively. Nutrients and chl a concentrations exhibited significant negative correlation for the whole water column (Spearman's $\rho, \rho=-0.76$, $p<0.01)$. No decrease of in vivo fluorescence was observed in the surface layers during the daylight period, indicating the absence of photoinhibition (Falkowski \& Kiefer 1985), linked to a decrease of primary production (Lizon et al. 1995); in vivo fluorescence and chl a were highly significantly correlated over the whole water column (Spearman's $\rho, \rho=0.89$, $\mathrm{p}<0.01$ ).

\section{Nitrite time series}

\section{Descriptive statistical analysis}

The time series of nitrite exhibit a very intermittent behaviour, where sharp fluctuations occurring on small scales are clearly visible (Fig. 3). Results of 
Table 1. Descriptive analysis of the 11 nitrite concentration time series. T: temporal resolution (s); SD: standard deviation

\begin{tabular}{|c|c|c|c|c|c|c|c|c|}
\hline \multirow[t]{2}{*}{ Time series } & \multicolumn{8}{|c|}{ Nitrite concentration $\left(\mu \mathrm{mol} \mathrm{l}^{-1}\right)$} \\
\hline & $\mathrm{N}$ & $\mathrm{T}$ & Mean & Min & $\operatorname{Max}$ & $\mathrm{SD}$ & Skewness & Kurtosis \\
\hline 1 & 999 & 3 & 0.10 & 0.05 & 0.29 & 0.03 & 1.97 & 5.80 \\
\hline 2 & 604 & 6 & 0.29 & 0.21 & 0.41 & 0.04 & 0.58 & 2.85 \\
\hline 3 & 659 & 6 & 0.11 & 0.03 & 0.31 & 0.05 & 0.39 & 3.83 \\
\hline 4 & 613 & 6 & 0.26 & 0.19 & 0.50 & 0.03 & 2.69 & 17.65 \\
\hline 5 & 1454 & 3 & 0.27 & 0.21 & 0.42 & 0.03 & 1.94 & 8.52 \\
\hline 6 & 1455 & 3 & 0.16 & 0.05 & 0.43 & 0.03 & 0.30 & 7.18 \\
\hline 7 & 1167 & 3 & 0.20 & 0.09 & 0.77 & 0.07 & 2.57 & 11.52 \\
\hline 8 & 1157 & 3 & 0.07 & 0.03 & 0.20 & 0.02 & 1.86 & 7.94 \\
\hline 9 & 1207 & 3 & 0.20 & 0.14 & 0.27 & 0.02 & 0.10 & 4.89 \\
\hline 10 & 1241 & 3 & 0.20 & 0.13 & 0.45 & 0.02 & 16.19 & 45.94 \\
\hline 11 & 1579 & 3 & 0.11 & 0.04 & 0.50 & 0.05 & 0.17 & 6.58 \\
\hline
\end{tabular}

descriptive analysis, including skewness and kurtosis estimates, for the 11 nitrite time series are presented in Table 1. The different time series of nitrite concentrations are not normally distributed (KolmogorovSmirnov test, p < 0.01; Lilliefors 1967) and their frequency distributions exhibit a skewed behaviour (Table 1), reflecting heterogeneous distributions with a few dense patches and a wide range of low-density patches.
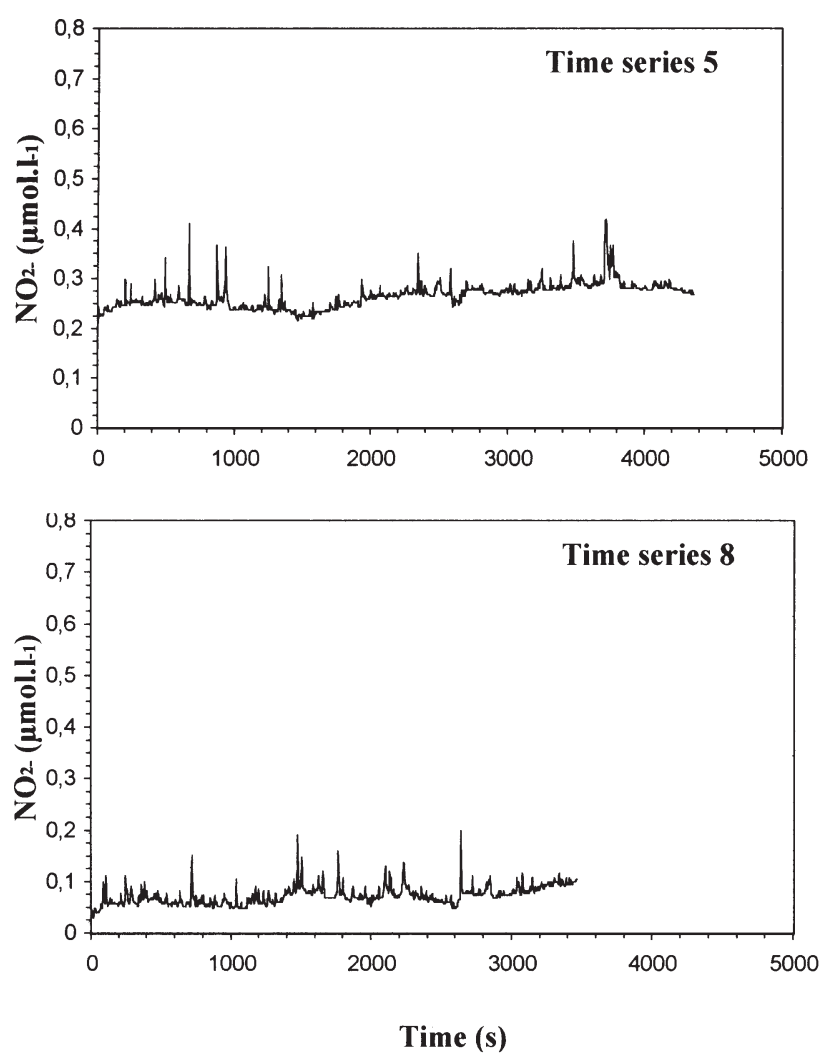

In order to validate our continuous use of the Technicon Autoanalyzer II, we computed the means of each time series and plotted them together with the evolution curves of the hourly estimates of nitrite concentrations (Fig. 4). Thus, means of the continuously recorded time series clearly appear to be very well integrated in the $12 \mathrm{~h}$ tidal cycle of the nitrite concentrations corresponding to our discrete sampling scheme at $2 \mathrm{~m}$ depth. More precisely, means of the
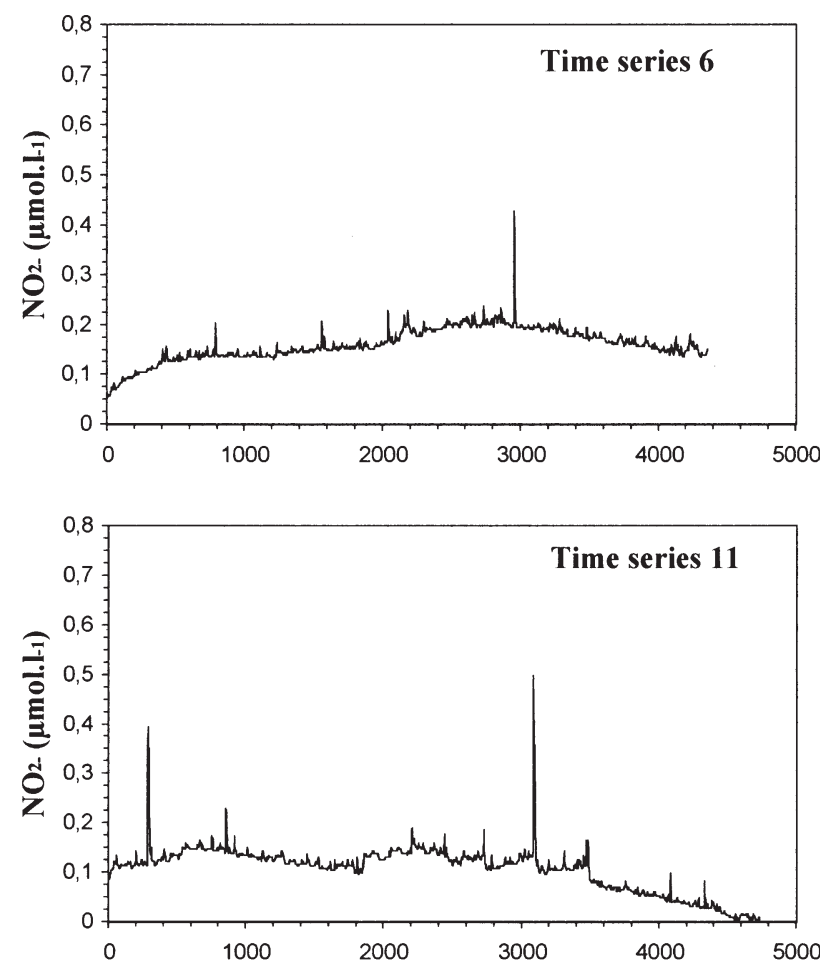

Time (s)

Fig. 3. Samples of high-resolution $(0.33 \mathrm{~Hz})$ nitrite concentration time series recorded in the eastern English Channel in high (time series 5 and 8) and low (time series 6 and 11) current speed conditions 


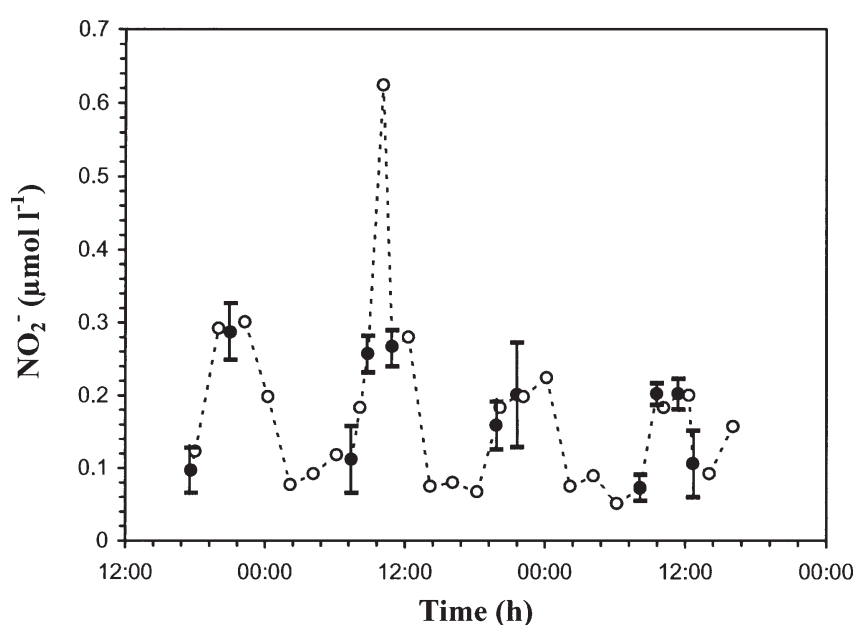

Fig. 4. Time series of nitrite concentrations (0) estimated from a $2 \mathrm{~m}$ depth sampling using Niskin bottles, shown together with the means $(\bullet)$ and standard deviations (vertical bars) of the 11 high-resolution nitrite time series continuously recorded at $0.25 \mathrm{~m}$ depth. Time in local hours
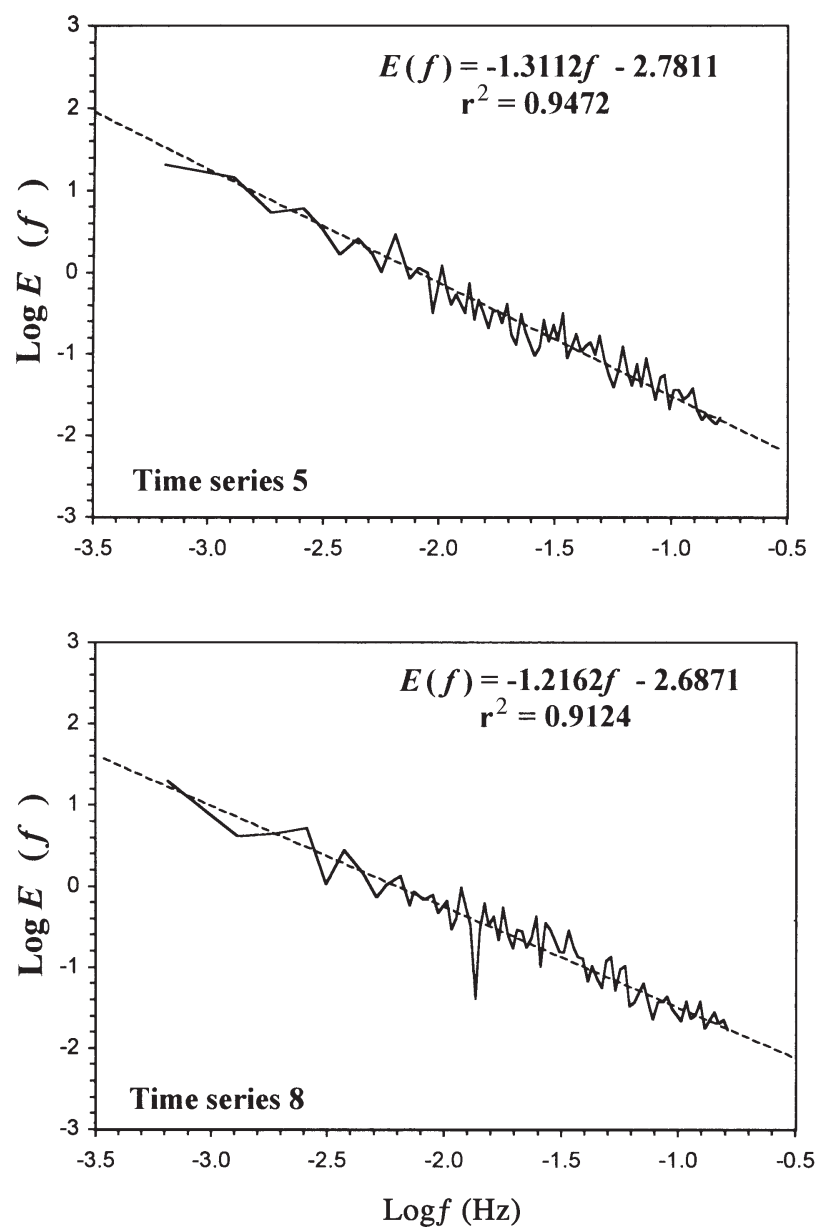

different time series cannot statistically be regarded as being different from the closest discrete estimate of nitrite concentration (Binomial test, $\mathrm{p}<0.05$; Siegel \& Castellan 1988), except in the case of the time series 4 .

\section{Fractal time series analysis}

The double logarithmic power spectra for the nitrite time series together with their best fitting lines are given in Fig. 5. Log-log linearity of power spectra is very strong for the whole range of scales considered, with coefficient of determination $\left(r^{2}\right)$ ranging from 0.76 to 0.95 . Those temporal scales can be associated with spatial scales using 'Taylor's hypothesis of frozen turbulence' (Taylor 1938), which basically states that temporal and spatial averages $t$ and 1 , respectively, can be related by a constant velocity $V$, with $l=V \cdot t$. Then, using the mean instantaneous tidal circulations
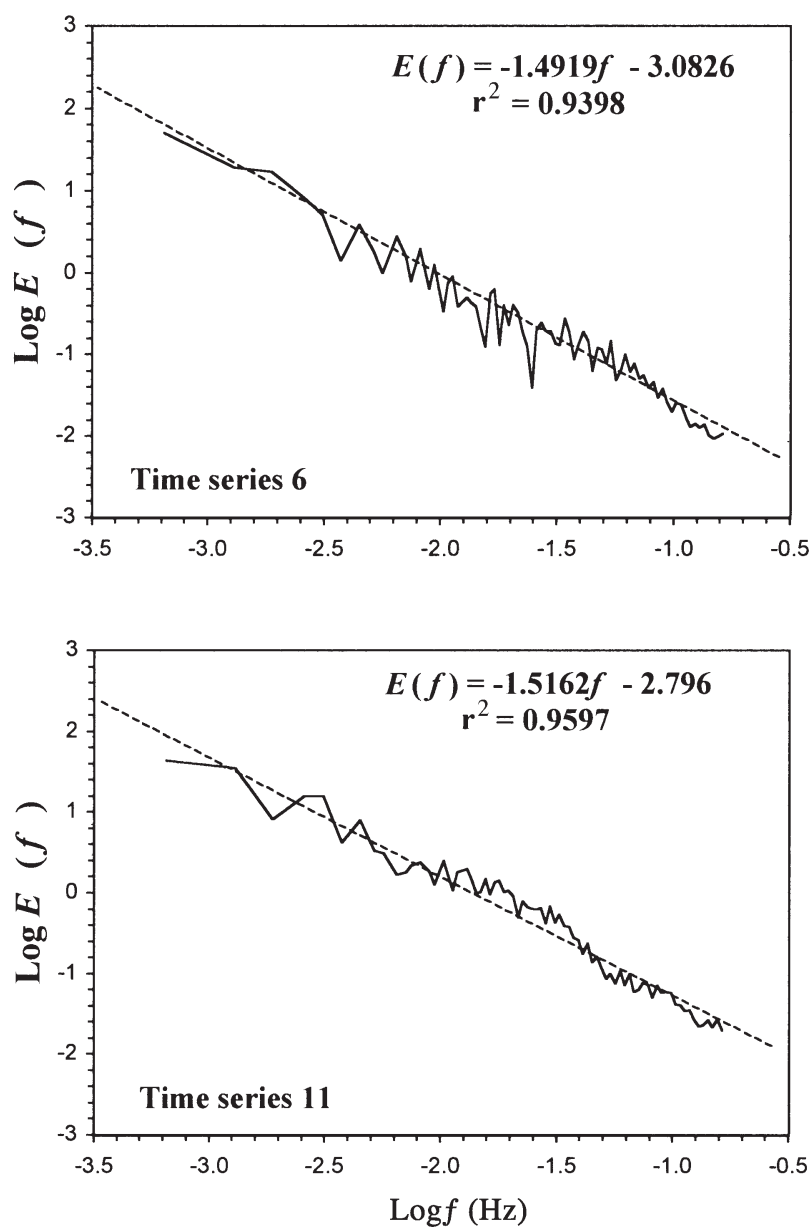

Fig. 5. The power spectra $E(f)$ ( $f$ is frequency) of the nitrite time series 5, 6, 8 and 11, shown together with their best-fitting lines in a log-log plot. The clear linearity of the power spectra indicates a scaling behaviour over the whole range of scales 
observed during the sampling of the different nitrite time series (Table 2), the spatial resolutions and extents associated to our sampling experiments ranges from 0.3 to $4 \mathrm{~m}$ respectively, and from 362 to $4926 \mathrm{~m}$ (Table 2). The spectral exponents $\beta$ (Table 3 ) lead to further conclusions (Fig. 6A). Indeed, an analysis of covariance concluded that the 11 spectral exponents $\beta$ were not all equal $(p<0.05)$. We then conducted a multiple comparison procedure based on the Tukey test (Zar 1984) to determine which $\beta$ was different from the others, and found that the slopes break into 2 homogeneous groups $\beta_{1}$ and $\beta_{2}$ including the series 2 , $3,6,7$ and 10 , and series $1,4,5,8,9$ and 11 , respectively (Table 3 ). Here as below, the subscripts 1 and 2 always refer to the time series $2,3,6,7,10$, and $1,4,5$, $8,9,11$, respectively. The fractal dimensions $D$, estimated from Eq. (5), then exhibit an inverted pattern (Fig. 6B), $D_{1}$ and $D_{2}$ being statistically different (Wilcoxon-Mann-Whitney $U$-test, $\mathrm{p}<0.05$; Table 3).
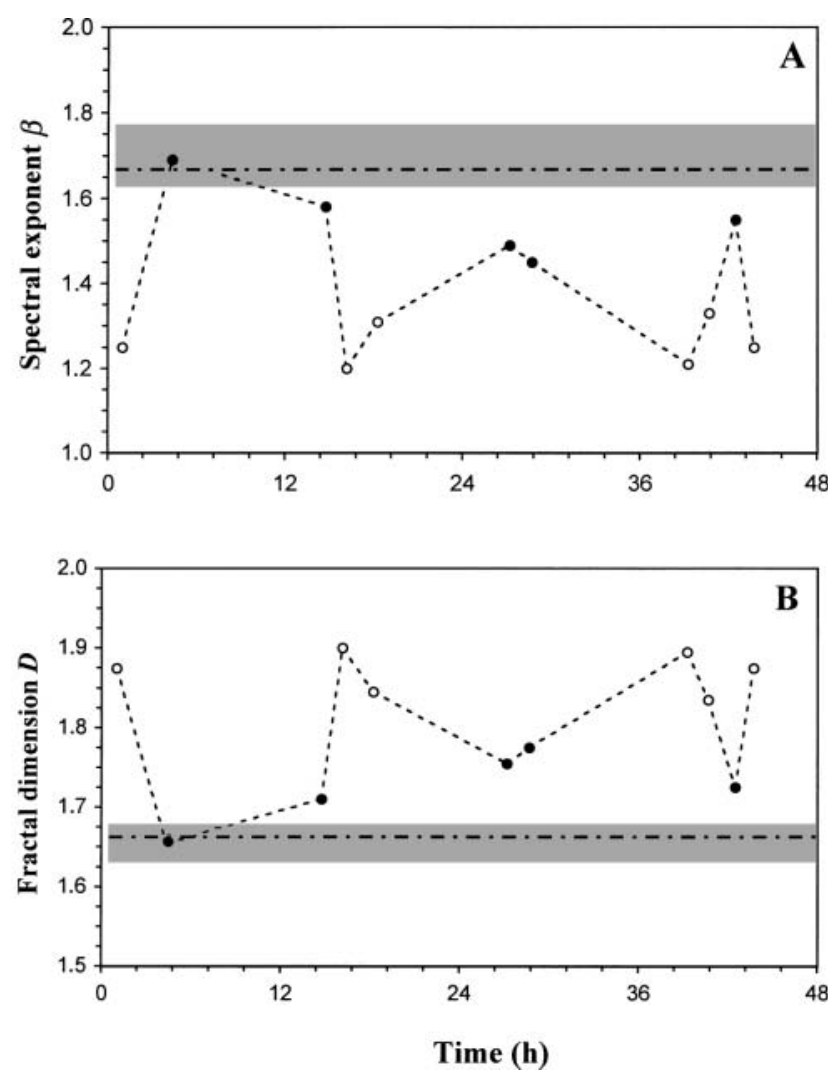

Fig. 6. Temporal patterns of the spectral exponent $\beta$ (A) and the fractal dimension $D$ (B). Straight broken lines correspond to the theoretical cases $\beta=5 / 3$ and $D=5 / 3$ (estimated with $\beta=5 / 3$ in Eq. 5). Black and open dots are associated with the time series $2,3,6,7,10$, and $1,4,5,8,9,11$, respectively, identified by subscripts 1 and 2 in the text. The shaded areas correspond to the $95 \%$ confidence intervals of the spectral exponents and fractal dimensions estimated from temperature and salinity time series
Table 2. Mean instantaneous tidal circulation $\left(C_{\text {speed }}\right)$ observed during the sampling of the nitrite time series, and the associated spatial resolution and extent

\begin{tabular}{|lccr|}
\hline Time series & $C_{\text {speed }}\left(\mathrm{m} \mathrm{s}^{-1}\right)$ & Resolution $(\mathrm{m})$ & Extent $(\mathrm{m})$ \\
\hline 1 & 0.55 & 1.65 & 1648.35 \\
2 & 0.10 & 0.60 & 362.40 \\
3 & 0.33 & 1.98 & 1304.82 \\
4 & 0.62 & 3.72 & 2280.36 \\
5 & 0.98 & 2.94 & 4274.76 \\
6 & 0.30 & 0.90 & 1309.50 \\
7 & 0.11 & 0.33 & 385.11 \\
8 & 0.87 & 2.61 & 3019.77 \\
9 & 0.73 & 2.19 & 2643.33 \\
10 & 0.18 & 0.54 & 670.14 \\
11 & 1.04 & 3.12 & 4926.48 \\
& & & \\
\hline
\end{tabular}

Similar analyses, conducted on the 11 temperature and salinity time series recorded simultaneously to the nitrite time series, lead to different results. While the double logarithmic power spectra of temperature and salinity exhibit strong linearity over the whole range of available scales (not shown), there is no difference between their exponents $\beta_{\mathrm{T}}$ and $\beta_{\mathrm{S}}$ (analysis of covariance, $\mathrm{p}>0.05$; Table 3 ). Moreover, the mean spectral exponent estimates $\beta$ for temperature, salinity and the previously identified 2 groups of nitrite time series are significantly different (Kruskal-Wallis test, $\mathrm{p}<0.05$ ), the nitrite exponents $\beta_{1}$ and $\beta_{2}$ being significantly smaller than those for temperature and salinity (Fig. 6A; Dunn test, p > 0.05; Siegel \& Castellan 1988). Similar conclusions can be drawn from fractal dimensions of temperature and salinity (Table 3), which cannot be distinguished and are significantly smaller than those of the nitrite time series (Fig. 6B).

Finally, we computed squared coherency between each nitrite time series and simultaneously recorded temperature and salinity time series in order to identify the scales at which nitrite might be coupled to temperature and salinity. Squared coherency never appeared to be significantly different from the one estimated from 2 synthetic random, uncorrelated time series presenting the same spectral exponents as the pairs of time series under consideration.

\section{Multifractal time series analysis}

The generalization of this spectral approach to higher orders of moment with the help of the $q^{\text {th }}$ order structure functions confirm the scaling previously shown by spectral analysis. Indeed, the nitrite structure functions, $<\left(\Delta \mathrm{NO}_{2}^{-}(\tau)\right)^{q}>$, clearly exhibit a linear behaviour as a function of scale in a log-log plot for different orders of moment (Fig. 7). The non-linearity 
Table 3. Mean values of the spectral exponent $\beta$, the fractal dimension $D$, and the universal multifractal parameters $H, C_{1}$, and $\alpha$ estimated for temperature, salinity time series, for the 11 nitrite time series (Nitrite $1 \& 2$ ) and the nitrite time series $2,3,6,7,10$ (Group 1) and 1, 4, 5, 8, 9, 11 (Group 2), recorded in high and low hydrodynamic conditions, respectively. Standard errors are given in brackets

\begin{tabular}{|lccccccccccc}
\hline & \multicolumn{2}{c}{$\beta$} & \multicolumn{2}{c}{$D$} & \multicolumn{2}{c}{$H$} & & $C_{1}$ & \\
Temperature & 1.70 & $(0.03)$ & 1.64 & $(0.02)$ & 0.40 & $(0.02)$ & & 0.060 & $(0.008)$ & 1.91 & $(0.01)$ \\
Salinity & 1.69 & $(0.03)$ & 1.65 & $(0.02)$ & 0.39 & $(0.02)$ & 0.062 & $(0.009)$ & 1.90 & $(0.01)$ \\
Nitrite (1 \& 2) & 1.40 & $(0.05)$ & 1.80 & $(0.02)$ & 0.30 & $(0.04)$ & 0.095 & $(0.01)$ & 1.87 & $(0.01)$ \\
Group 1 & 1.55 & $(0.04)$ & 1.72 & $(0.02)$ & 0.42 & $(0.02)$ & 0.140 & $(0.01)$ & 1.84 & $(0.02)$ \\
Group 2 & 1.26 & $(0.02)$ & 1.87 & $(0.01)$ & 0.21 & $(0.01)$ & 0.070 & $(0.01)$ & 1.89 & $(0.01)$ \\
\hline
\end{tabular}

of the exponents $\zeta(q)$ (not shown) indicates that the small-scale distributions of nitrite can be considered as multifractals. More specifically, the scaling of the first moments $\zeta(1)=H$ leads to a behaviour very simi- lar to the one observed in the case of the spectral exponents $\beta$ (Fig. 8A); an analysis of covariance and an appropriate multiple comparison procedure also lead to distinguish 2 groups of $H$ values (Table 3 ). The
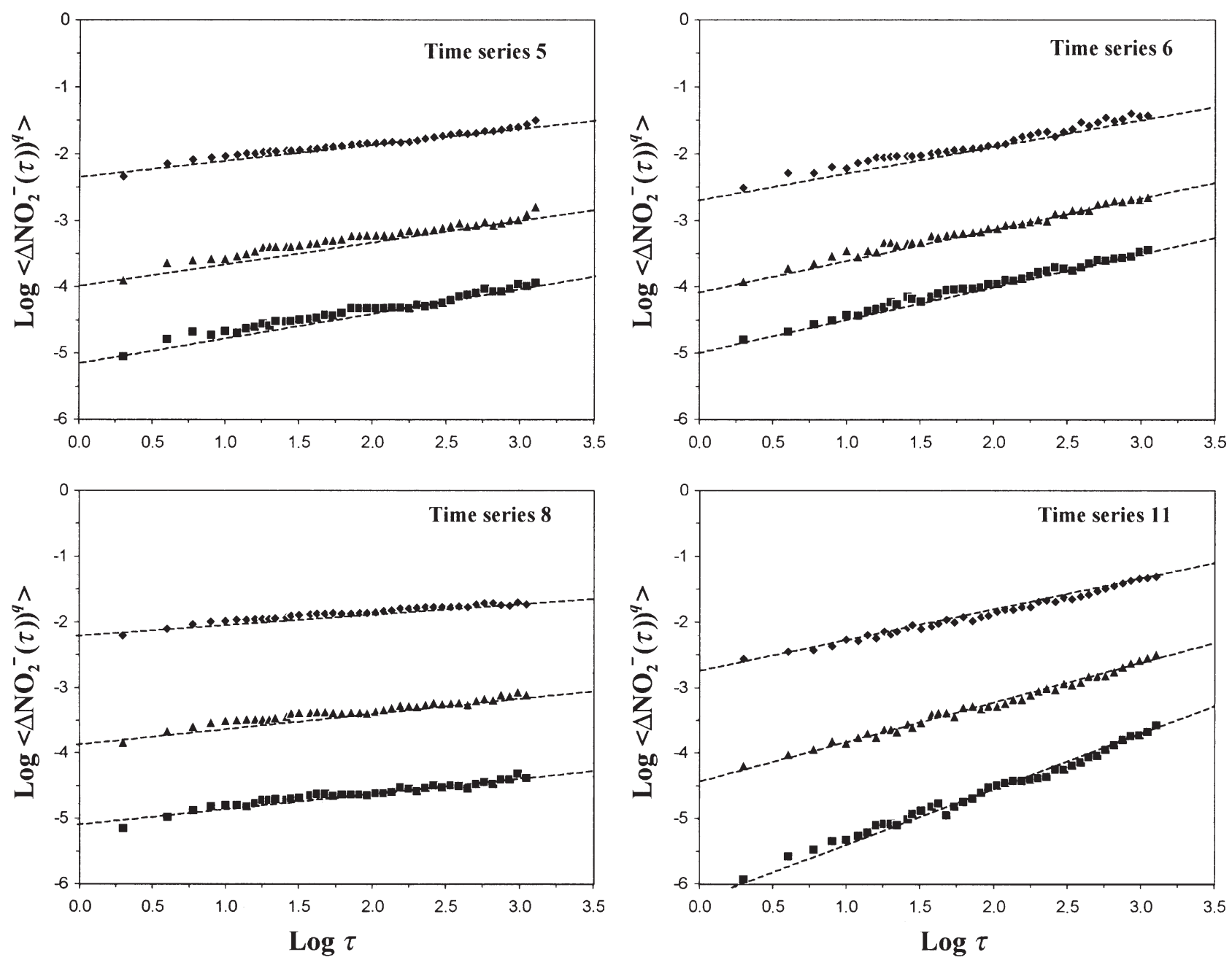

Fig. 7. The structure functions $<\left(\Delta \mathrm{NO}_{2}{ }^{-}(\tau)\right)^{q}>$ vs $\tau$ in $\log$-log plots for $q=1,2$ and 3 (from top to bottom) for time series 5, 6, 8 and 11. As shown in the case of power spectral analysis, the data are scaling over the whole range of scales. The slopes of the straight dashed lines provide estimates of the first, second and third moment scaling exponents $\zeta(1)=H, \zeta(2)$ and $\zeta(3)$ 

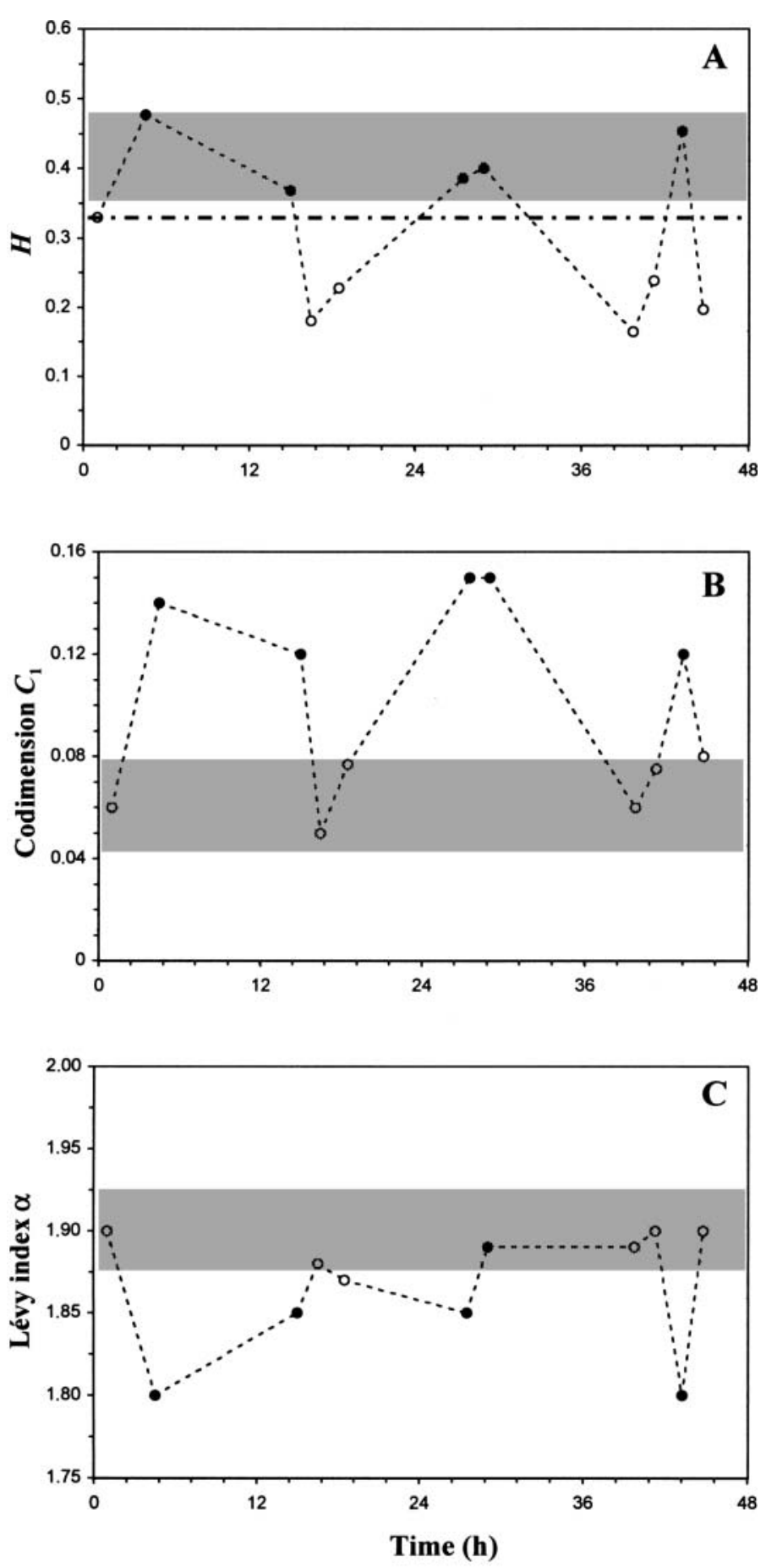

Fig. 8. Temporal patterns of the universal multifractal parameters $H(\mathrm{~A}), C_{1}(\mathrm{~B})$ and $\alpha(\mathrm{C})$. Black and open dots are associated with the time series $2,3,6,7,10$, and $1,4,5,8,9,11$, respectively, identified by the subscript 1 and 2 in the text. The straight broken line in (A) corresponds to the theoretical case $H=1 / 3$ expected for purely passive scalar in ObukhovCorrsin homogeneous turbulence. The shaded areas correspond to the $95 \%$ confidence intervals of the universal multifractal parameters estimated from the temperature and salinity time series universal multifractal parameters $C_{1}$ and $\alpha$ (Table 3 ) also exhibit a variable behaviour from one time series to another (Fig. 8B,C), suggesting a differential control of the organization of the $\mathrm{NO}_{2}^{-}$variability over time. Namely, $C_{1_{1}}$ and $C_{1_{2}}$, as well as $\alpha_{1}$ and $\alpha_{2}$, are significantly different (Wilcoxon-Mann-Whitney $U$ test, $\mathrm{p}<0.05$ ).

Similar analyses of temperature and salinity indicate that the first universal multifractal parameter $H$ does not exhibit significant difference from one time series to another ( $p>0.05$ ) (Table 3 ) and are indistinguishable from the first group of $H$ values and significantly higher than the second group of $H$ values estimated for nitrite time series (Table 3 ). Second, the parameters $C_{1}$ shared by the temperature and salinity time series $(\mathrm{p}>$ $0.05)$ are significantly smaller than the $C_{1}$ values estimated for the first group of the nitrite time series, and not significantly different from that for the second group (Fig. 8B; Table 3). Finally, the parameters $\alpha$ estimated for the temperature and salinity time series (Table 3) are indistinguishable ( $p>0.05)$, but appear to be significantly higher than that estimated parameters for the first group of the nitrite time series, and not significantly different from that for the second group (Dunn test, p <0.05; Fig. 8C; Table 3).

\section{Correlation analyses}

In order to determine the factors influencing the magnitude of the differential structure levels of nitrite time series represented by the fractal dimension $D_{\text {, }}$ and the universal multifractal parameters $H, C_{1}$ and $\alpha$, we conducted correlation analyses between these parameters, the integrals of the nitrite spectra (i.e. an estimate of the total variation in a given record; Bendat \& Piersol 1986), the means of the nitrite time series and chl a concentrations estimated from $2 \mathrm{~m}$ depth water samples during each time series recording, and the current speed and direction, as an indicator of the physical forcings (Table 4). These analyses showed that the fractal and multifractal structures of nitrite variability were not correlated with the mean nitrite and chl a concentrations, nor with the integral of the nitrite spectra (Spearman's $\rho$, 2-tailed, $90 \%$ level, p > 0.05). Moreover, the absence of correlation between fractal and multifractal parameters and current direction also indicates that the structure of nitrite variability cannot be related with the horizontal advection processes associated with the M2 tidal component. Instead, fractal and multifractal parameters were significantly correlated with current speed (Spearman's $\rho$, 2-tailed, $\mathrm{p}<0.05$ and $\mathrm{p}<0.01$; see Table 4), suggesting a differential hydrodynamic control of the structure of nitrite variability. 
Table 4. Correlation matrix of variables relative to the structure of nitrite time series. $\mathrm{NO}_{2}^{-}$mean and $\mathrm{NO}_{2}^{-}$spectral sum: mean concentration of nitrite time series and sum of the nitrite power spectra; $D$ : fractal dimension; $H_{1} C_{1}$, and $\alpha$ : universal multifractal parameters; $C_{\text {speed }}$ and $C_{\text {direction: }}$ current speed and direction. ${ }^{*} 5 \%$ significance level; ${ }^{* *} 1 \%$ significance level

\begin{tabular}{|lcccccccc|}
\hline & $\mathrm{NO}_{2}^{-}$mean & $\mathrm{NO}_{2}^{-}$spectral sum & $D$ & $H$ & $C_{1}$ & $\alpha$ & $C_{\text {speed }}$ & $C_{\text {direction }}$ \\
\hline $\mathrm{NO}_{2}^{-}$mean & 1.000 & - & - & - & - & - & - & - \\
$\mathrm{NO}_{2}^{-}$spectral sum & -0.150 & 1.000 & - & - & - & - & - & - \\
$D$ & -0.347 & -0.187 & 1.000 & - & - & - & - & - \\
$H$ & 0.489 & 0.169 & $-0.927^{* *}$ & 1.000 & - & - & - & - \\
$C_{1}$ & 0.177 & 0.380 & $-0.805^{* *}$ & $0.846^{* *}$ & 1.000 & - & - & - \\
$\alpha$ & -0.512 & 0.097 & $0.690^{*}$ & $-0.648^{*}$ & -0.509 & 1.000 & - & - \\
$C_{\text {speed }}$ & -0.305 & -0.191 & $0.724^{*}$ & $-0.815^{* *}$ & $-0.654^{*}$ & $0.610^{*}$ & 1.000 & - \\
$C_{\text {direction }}$ & -0.509 & -0.124 & 0.184 & -0.401 & -0.370 & 0.234 & 0.014 & 1.000 \\
\hline
\end{tabular}

\section{DISCUSSION}

\section{Sampling small-scale nutrient patches}

The differences observed between the values of the multifractal parameters $H, C_{1}$ and $\alpha$ estimated from nitrite time series, like the differences between these parameters and those estimated from in vivo fluorescence, temperature and salinity time series in previous studies (Seuront et al. 1996a,b, 1999), cannot be associated with the different spatial resolutions and extents associated with each nitrite time series (see Table 2), nor with the differences between nutrient and temperature, salinity and in vivo fluorescence sampling techniques. In the former case, we should have observed a transition between 2 different scaling regimes, both in power spectra and structure function log-log plots. This is obviously not the case here (see Figs. 5 \& 7 , respectively). In the latter case, the temporal and spatial resolutions of previous studies (i.e. 0.5 to $1 \mathrm{~s}$, and 0.3 to $1 \mathrm{~m}$, respectively), the small sizes and the minute time scales of the response of the temperature, salinity and in vivo fluorescence sensors lead to sampling conditions very similar to those reached in the present study.

On the other hand, we argue here that our sampling process cannot be regarded as affected by the motion of the ship, nor the characteristics of the sample processing chain including features of the electronics involved. First, a contamination by the motion of the ship (our pumping system did not move except with the ship) would have been indicated by peaks at characteristic frequencies or time scales (Jenkins \& Watts 1968), which is clearly not the case in our data (see Figs. 3, $5 \& 7$ ). Second, the linearity of the nitrite power spectra over the whole range of available scales indicates the absence of any kind of noise contamination by the electronics or the processing chain, in which case the high-frequency part of the spectra would have shown a roll-off towards the noise level of the involved electronics. The absence of this characteristic signa- ture of high-frequency noise demonstrates that our sampling frequency is well above the electronic noise level (Jenkins \& Watts 1968).

\section{Fractal versus multifractal analyses}

The differences in the temporal patterns of variability exhibited by the fractal dimension $D$ and the universal multifractal parameters $H, C_{1}$ and $\alpha$ estimated from the nitrite time series clearly demonstrate the ability of multifractal analysis to provide more complete information than the results obtained from fractal analysis. Using only fractal dimensions $D$ would have led to viewing the local temporal patterns of nitrite time series as independent of physical processes: the spectral exponents $\beta$ are significantly different from the theoretical value expected in the case of a purely passive scalar, and the fractal dimensions estimated from nitrite time series, and from temperature and salinity time series are significantly different (cf. Fig. 6). The correlation observed between fractal dimension and current speed then only suggests an indirect control of nitrite fractal structure by hydrodynamic processes. In contrast, the universal multifractal parameters temporal distributions revealed coupling and uncoupling between nitrite distribution and physical processes, as a function of tidal current intensity. Such observations then demonstrate that marine ecologists should focus on the precise nature of the distribution of patterns and processes in question in order to obtain more relevant information on the driving processes responsible for the observed variability.

\section{Small-scale nutrient patches and hydrodynamic conditions}

In well-mixed environments where turbulent processes are fully developed, previous empirical studies have demonstrated that fluctuations of biological para- 
meters (e.g. phytoplankton biomass) could follow a spectral power law behaviour marked by a characteristic exponent $\beta(\beta=5 / 3)$ over a wide range of scales (e.g. Seuront et al. 1996a,b, 1999), as theoretically expected in the case of purely passive scalars (i.e. temperature or salinity) advected by turbulent processes. However, except in the case of the time series 2, our estimates of the spectral exponent $\beta$ are significantly different from the previously defined theoretical value $(\beta=5 / 3)$. This observation indicates that the small-scale variability of the $\mathrm{NO}_{2}^{-}$time series cannot be regarded as being purely passively driven by turbulent fluid motion and that there could exist an additional level of complexity in the origin of the structure of $\mathrm{NO}_{2}{ }^{-}$variability. Moreover, the high fractal dimensions associated with strong current speeds characterize very complex processes where short-range, local variability is highly developed and tends to obfuscate long-range trends perceptible from lower fractal dimensions, associated with weak current speed; $\mathrm{NO}_{2}^{-}$is thus more evenly distributed under high turbulence.

The negative correlation between $H$ and the fractal dimensions $D$ confirms the results of the monofractal analysis. The first universal multifractal parameter $H$ characterizes the degree of non-conservation of the process. The lower $H$ is, the more conservative is the corresponding process, i.e. the mean of the fluctuations is less scale-dependent, indicating a reduced flux of variance from large to smaller scales, and thus the prevalence of local variability.

Under low turbulence the higher values of $C_{1}$ indicate the occurrence of few patches of high $\mathrm{NO}_{2}^{-}$concentrations that are several orders of magnitude above background levels. Under higher turbulence the lower $C_{1}$ indicates that $\mathrm{NO}_{2}{ }^{-}$is more homogeneously distributed (Fig. 3) and behaves as a passive scalar. This hypothesis is supported by observations that the $C_{1}$ values observed for nitrite time series under high turbulence cannot be distinguished from the $C_{1}$ values estimated for temperature and salinity irrespective of hydrodynamic conditions. Here the so-called homogenisation effect is mainly perceptible from the disruption of these patches (see Fig. 3). $\mathrm{NO}_{2}^{-}$distribution nevertheless remains heterogeneous (i.e. structured) irrespective of the hydrodynamic conditions, as the parameter $C_{1}$ is significantly greater than 0 ( $\mathrm{p}<$ 0.05), in which case the nitrite would have been homogeneously distributed.

Finally, the mean value of $\alpha$ indicates that $\mathrm{NO}_{2}^{-}$cannot be regarded as log-normally distributed, in which case $\alpha=2$. On the contrary, this value is typically in the range of $\alpha$ values estimated for phytoplankton biomass, temperature and salinity distribution over similar ranges of scales (see Seuront et al. 1996a,b, 1999, present study). Nevertheless, our results indicate a dif- ferential $\mathrm{NO}_{2}{ }^{-}$structure characterized by a greater complexity in the hierarchy of its variability levels under high turbulence (Table 4).

\section{Small-scale nutrient patches and phytoplankton patchiness}

A comparison of the fractal and multifractal parameters estimated for nitrite time series and those of phytoplankton biomass warrants further comments. The fractal dimensions $D$ are higher than those found for phytoplankton biomass distribution by Seuront \& Lagadeuc (1998) and Seuront et al. (1996a) during neap tide, and by Seuront et al. (1996b, 1999) during spring tide; fractal dimensions were estimated using the $\beta$ values reported by Seuront et al. (1996a,b, 1999) in Eq. (5). That indicates that the processes generating the nitrite variability could be associated with smaller-scale variability than the processes responsible for the small-scale distribution of phytoplankton biomass, under all hydrodynamic conditions. These observations are specified by the values of the first and second universal multifractal parameters $H$ and $C_{1}$. The former and the latter, when estimated for nitrite time series recorded in strong and low turbulence (Table 3), are significantly smaller and larger than the values reported by Seuront et al. (1996a,b, 1999) for phytoplankton, temperature and salinity distributions, and for temperature and salinity in the present study (Fig. 8A,B). In contrast, the third universal multifractal parameter $\alpha$ values estimated from nitrite time series are significantly higher than the values estimated from phytoplankton biomass in the eastern English Channel and the Southern Bight of the North Sea. These results, suggesting a very specific structure of nitrite variability, irrespective of the external physical and/or biological forcings, thus show that the small-scale distribution of nitrite is (1) characterized by the prevalence of a more local variability (low $H$ ) in comparison with phytoplankton biomass under high turbulence, (2) more heterogeneous (high $C_{1}$ ) than phytoplankton biomass distribution over similar ranges of scales in weak turbulence, and (3) less complex than phytoplankton distributions under all hydrodynamic conditions.

\section{Small-scale nutrient patchiness: towards a mechanistic interpretation}

The organization of $\mathrm{NO}_{2}^{-}$variability cannot be regarded as density-dependent, whereas Seuront \& Lagadeuc (1998) found a strong density-dependence of phytoplankton biomass structure (estimated on the 
basis of a monofractal analysis) in relation with both the inshore-offshore gradient and the horizontal advection processes characterizing the coastal waters of the eastern English Channel. However, a source of $\mathrm{NO}_{2}^{-}$in marine waters being its release by phytoplankton populations that are growing on nitrate (McCarthy et al. 1984), the observed heterogeneity in the $\mathrm{NO}_{2}{ }^{-}$distributions could be connected to the occurrence of the prymnesiophyceae Phaeocystis sp., which reached high concentrations during the sampling experiment (Truffier et al. 1997). This species being known for its highly developed swarming capacities along the English coast of the eastern English Channel (Tyler 1977, Lennox 1979), we could suggest 2 nonconflicting hypotheses for the observed nitrite heterogeneous distributions:

(1) The aggregation properties of Phaeocystis and the associated potential release of nitrite can be regarded as a direct source of heterogeneity for nitrite concentrations.

(2) The presence of Phaeocystis aggregates could provide highly favourable microhabitats for microplankton populations (Mitchell et al. 1985, Mitchell \& Fuhrman 1989) and thus lead to an indirect source of patchiness for nutrient distributions.

The observed heterogeneous distributions of nitrite concentrations would on the one hand be a direct consequence of the heterogeneous distribution of Phaeocystis $\left(\mathrm{NO}_{2}^{-}\right.$release), and on the other hand the result of the interactions between the heterogeneous distribution of phytoplankton cells and the associated clustering of bacteria. In that way, the degradation of Phaeocystis can also be regarded as a potential secondary source of nutrient patchiness. Indeed, the degradation of phytoplankton cells has been widely shown to be a source of patchiness and taxonomic diversity for bacterioplankton populations (Wilcox Silver et al. 1978, Blight et al. 1995), and then a likely patchy nutrient resource. In both cases, an increase in turbulence leads to the disruption of Phaeocystis aggregates-as suggested by previous works on phytoplankton coagulation (e.g. Riebesell 1991a,b) — and/or the disruption of the bacterial clusters existing around phytoplankton cells (Bowen et al. 1993). They could thus be regarded as a potential source of homogenisation, as shown from the values of the universal multifractal parameter $C_{1}$ (see also Fig. 3). One may note the absence of any circadian periodicity in the mean nitrite concentration and in the structure of nitrite variability. This lack of periodicity shows that during the sampling experiment nitrifying bacterial production was not photoinhibited - as previously demonstrated elsewhere (Gentilhomme 1993, Gentilhomme \& Raimbault 1995) — and is consistent with our second hypothesis (i.e. role of nitrifying and/or denitrifying bacteria in the $\mathrm{NO}_{2}{ }^{-}$structure).
The hypotheses related to the origin of the differential temporal structure of nitrite variability nevertheless need to be tested both in the field and by way of numerical experiments. Simultaneous measurements of nitrite and phytoplankton concentration, bacterial abundance and activity under different hydrodynamic conditions - known to influence bacterial production rates (e.g. Confer \& Logan 1991, Logan \& Kirchman 1991) - could be helpful in determining the sources of the nutrient patches, especially at low flow speed. On the other hand, numerical simulations of the differential aggregative properties of phytoplankton and bacterial populations relative to the physical forcing of turbulent processes could lead to a better understanding of the small-scale patch formation and maintenance. Indeed, Blackburn et al. (1998) demonstrated that spherical patches a few millimeters in diameter could sustain swarms of bacteria for about 10 min, and Blackburn \& Fenchel (1999) numerically showed that moderate shear does not significantly alter patch volumes within the time scales of several minutes. Such information is still not available in turbulent environments.

\section{CONCLUSION}

This study demonstrates the validity of our high resolution (i.e. a 3 s temporal resolution) dissolved nitrogen continuous sampling technique and its applicability to the distribution of nitrite in a highly dissipative environment. On the basis of a unique dataset of 11 temperature, salinity and nitrite time series simultaneously recorded in the eastern English Channel, we demonstrate that the distribution of nitrite is patchy under all hydrodynamic conditions, that this patchiness can be very specific, different from the one exhibited by purely passive scalars such as temperature and salinity, or phytoplankton cells, and can be thought of as the result of complex interactions between hydrodynamic conditions, biological processes related to phytoplankton populations, and bacterial activity. Additionally, while the applicability of fractal and multifractal algorithms to marine studies is now widely recognized (e.g. Frontier 1987, Sugihara \& May 1990, Pascual et al. 1995, Seuront et al. 1999), this study clearly shows that a multifractal framework can generate useful and unique information for an understanding of the spatio-temporal structure of marine systems.

The previously demonstrated small-scale heterogeneity of nitrite distribution presents several implications on the structure and the functioning of the pelagic food-web:

(1) In particular, the observed small-scale nutrient patchiness is of prime interest in the estimates of phytoplankton growth considering the importance of 
nutrient 'surge uptake' by phytoplankton in the presence of ephemeral point sources of nutrients (e.g. Collos 1983, Raimbault \& Gentilhomme 1990). However, such estimates will still suffer from the lack of both any adequate model of uptake under non-steady state conditions and any convergent empirical evidence of the effect of a heterogeneous nutrient distribution on phytoplankton uptake and growth.

(2) Heterogeneous nutrient distribution or, more generally, small-scale heterogeneity of resources and consumers in the ocean could provide a potential phenomenological explanation to the persistence of local high phytoplankton diversity in highly energetic areas (Hutchinson 1961) referred to as the 'paradox of the plankton'. Indeed, heterogeneous distributions of resources could be regarded as a source of patchiness for higher and lower trophic levels, such as detritus and marine snow for microbial communities (Azam 1998).

(3) The temporal differential structure of nutrient distribution shown in the present work indicates that the size of the elemental structures of the observed patterns was related to the available energy (the tidal current velocity here), as proposed by Margalef (1979), but also to the biological response of micro-organisms to physical forcing (disruption of patches under elevated turbulence).

Further extensions of these ideas and observations are still needed to achieve a more complete understanding of the small-scale spatio-temporal couplings between a heterogeneous nutrient supply and utilization of the different components of the oceanic nitrogen cycling by phytoplankton populations.

Acknowledgements. We acknowledge the captain and the crew of the NO 'Côte d'Aquitaine' for their cooperation, Ms $\mathrm{N}$. Esquerre for her help in the data processing and measuring out of nitrite and nitrate concentrations, Mr D. Hilde for the extraction of chl $a$, as well as Ms N. Jobert and Mr B. Vignolle for excellent assistance during the cruise. We enjoyed our conversation with Dr F. Schmitt and acknowledge his helpful advice on multifractals. The authors would like to thank Prof. H. Yamazaki and Dr J. G. Mitchell for stimulating discussions, and 4 anonymous reviewers for constructive criticisms of an earlier version of this work. Ms V. Pasour kindly improved the language.

\section{LITERATURE CITED}

Abbott MA, Beltrami E, Richerson PJ (1982) The relationship of environmental variability to the spatial patterns of phytoplankton biomass in Lake Tahoe. J Plankton Res 4: 927-941

Azam F (1998) Microbial control of oceanic carbon flux: the plot thickens. Science 280:694-696
Bendat JS, Piersol AG (1986) Random data: analysis and measurement procedures, 2nd edn. John Wiley, New York

Bentley D, Lafite R, Morley NH, James R, Statham PJ, Guary JC (1993) Flux de nutriements entre la Manche et la Mer du Nord. Situation actuelle et évolution depuis dix ans. Oceanol Acta 16:599-606

Blackburn N, Fenchel T (1999) Influence of bacteria, diffusion and shear on micro-scale nutrient patches, and implications for bacterial chemotaxis. Mar Ecol Prog Ser 189:1-7

Blackburn N, Fenchel T, Mitchell J (1998) Microscale nutrient patches in planktonic habitats shown by chemotactic bacteria. Science 282:2254-2256

Blight SP, Bentley TL, Lefevre D, Robinson C, Rodrigues R, Rowland J, Williams PJ (1995) Phasing of autotrophic and heterotrophic plankton metabolism in a temperate coastal ecosystem. Mar Ecol Prog Ser 128:61-75

Bowen JD, Stolzenbach KD, Chisholm SW (1993) Simulating bacterial clustering around phytoplankton cells in a turbulent ocean. Limnol Oceanogr 38:36-51

Bowers DG, Simpson JH (1987) Mean position of tidal fronts in Europen-shelf seas. Cont Shelf Res 7:35-44

Brunet C, Brylinski JM, Lemoine Y (1993) In situ variations of the xanthophylls dioxanthin and diadinoxanthin: photoadaptation and relationships with a hydrodynamical system in the eastern English Channel. Mar Ecol Prog Ser 102:69-77

Brylinski JM, Dupont J, Bentley D (1984) Conditions hydrologiques au large du cap Griz-Nez (France): premiers résultats. Oceanol Acta 7:315-322

Brylinski JM, Bentley D, Quisthoudt C (1988) Discontinuité écologique et zooplancton (copépodes) en Manche orientale. J Plankton Res 10:503-513

Brylinski JM, Lagadeuc Y, Gentilhomme V, Dupont JP and 7 others (1991) Le 'fleuve côtier': un phénomène hydrologique important en Manche orientale: exemple du Pas-de-Calais. Oceanol Acta 11:197-203

Collos Y (1983) Transient situations in nitrate assimilation by marine diatoms. 4. Non-linear phenomena and the estimation of the maximum uptake rate. J Plankton Res 5: 677-691

Confer DR, Logan BE (1991) Increased bacterial uptake of macromolecular substrates with fluid shear. Appl Environ Microbiol 57:3093-3100

Denman KL, Abbott MR (1994) Time scales evolution from cross-spectrum analysis of advanced very high resolution radiometer and coastal zone color scanner imagery. J Geophys Res 99:7433-7442

Estrada M, Wagensberg M (1977) Spectral analysis of spatial series of oceanographic variables. J Exp Mar Biol Ecol 30: 147-164

Falkowski PG, Kiefer DA (1985) Chl a fluorescence in phytoplankton: a comparative field study. J Mar Res 7:715-731

Falkowski PG, Barber RT, Smetacek V (1998) Biogeochemical controls and feedbacks on ocean primary production. Science 281:200-206

Fasham MJR (1978) The statistical and mathematical analysis of plankton patchiness. Oceanogr Mar Biol Annu Rev 16: 43-79

Frontier S (1987) Applications of fractal theory to ecology. In: Legendre P, Legendre L (eds) Developments in numerical ecology. Springer-Verlag, Berlin, p 335-378

Fuller WA (1976) An introduction to statistical time series. John Wiley, New York

Gentilhomme V (1993) Quantification des flux d'absorption et de régénération de l'azote minéral (nitrate, nitrite et ammonium) et organique (urée) dans la couche euphotique des océans oligotrophes. PhD thesis, University of Aix-Marseille II 
Gentilhomme V, Lizon F (1998) Seasonal cycle of nitrogen and phytoplankton biomass in a well-mixed coastal system (Eastern English Channel). Hydrobiologia 361:191-199

Gentilhomme V, Raimbault P (1995) Absorption et régénération de l'azote dans la zone frontale du courant Algérien (Méditerranée Occidentale): réévaluation de la production nouvelle. Oceanol Acta 17:555-562

Hutchinson GE (1961) The paradox of the plankton. Am Nat 95:137-146

Itsweire EC, Osborn TR, Stanton TP (1989) Horizontal distribution and characteristics of shear layers in the seasonal thermocline. J Phys Oceanogr 10:301-320

Jenkins G, Watts D (1968) Spectral analysis and its applications. Holden-Day, San Francisco

Jickells TD (1998) Nutrient biogeochemistry of the coastal zone. Science 281:217-222

Kendall M, Stuart A (1966) The advanced theory of statistics. Hafner, New York

Lagadeuc Y, Brylinski JM, Aelbrecht D (1997) Temporal variability of the vertical stratification of a front in a tidal Region of Freshwater Influence (ROFI) system. J Mar Res 12:147-155

Lennox A (1979) Studies of the ecology and physiology of Phaeocystis. PhD thesis, University of Wales

Lilliefors HW (1967) On the Kolmogorov-Smirnov test for normality with mean and variance unknown. J Am Stat Assoc 64:387-389

Lizon F, Lagadeuc Y, Brunet C, Aelbrecht D, Bentley D (1995) Primary production and photoadaptation of phytoplankton in relation with tidal mixing in coastal waters. J Plankton Res 17:1039-1055

Logan BE, Kirchman DL (1991) Uptake of dissolved organics by marine bacteria as a function of fluid motion. Mar Biol 111:175-181

Mackas DL, Denman KL, Abbott MR (1985) Plankton patchiness: biology in the physical vernacular. Bull Mar Sci 37: 652-674

MacKenzie BR, Leggett WC (1991) Quantifying the contribution of small-scale turbulence to the encounter rates between larval fish and their zooplankton prey: effects of wind and tide. Mar Ecol Prog Ser 73:149-160

MacKenzie BR, Leggett WC (1993) Wind-based models for estimating the dissipation rates of turbulence energy in aquatic environments: empirical comparisons. Mar Ecol Prog Ser 94:207-216

Mandelbrot B (1977) Fractals. Form, chance and dimension. WH Freeman, London

Mandelbrot B (1983) The fractal geometry of nature. WH Freeman, New York

Mann KH, Lazier JRN (1991) Dynamics of marine ecosystems. Biological-Physical interactions in the oceans. Blackwell, Boston

Margalef R (1967) Some concepts relative to the organization of plankton. Oceanogr Mar Biol Annu Rev 5:257-289

Margalef R (1979) The organization of space. Oikos 33:152-159

McCarthy MD, Kaplan JJ, Nevins JL (1984) Chesapeake Bay nutrient and plankton dynamics. 2. Sources and sinks of nitrite. Limnol Oceanogr 29:84-98

McCarthy MD, Hedges JI, Benner R (1998) Major bacterial contribution to marine dissolved organic nitrogen. Science 281:231-234

Mitchell JG, Fuhrman JA (1989) Centimeter scale vertical heterogeneity in bacteria and chl a. Mar Ecol Prog Ser 54: 141-148

Mitchell JG, Okubo A, Fuhrman JA (1985) Microzones surrounding phytoplankton form the basis for a stratified marine microbial ecosystem. Nature 316:58-59
O'Neill R (1971) Function minimization using a simplex procedure. Appl Stat 21:338-343

Pascual M, Ascioti FA, Caswell H (1995) Intermittency in the plankton: a multifractal analysis of zooplankton biomass variability. J Plankton Res 17:1209-1232

Platt T (1972) Local phytoplankton abundance and turbulence. Deep-Sea Res 19:183-187

Platt T (1975) The physical environment and spatial structure of phytoplankton populations. Mém Soc R Sci Liège 7:9-17

Platt T, Denman KL (1975) Spectral analysis in ecology. Annu Rev Ecol Syst 6:189-210

Platt T, Sathyendranath S, Ulloa O, Harrison WG, Hoepffner N, Goes J (1992) Nutrient control of phytoplankton photosynthesis in the Western North Atlantic. Nature 356: 229-231

Powell TM, Richerson PG, Dillon TM, Agee BA, Dozier BJ Godden DA, Myrup LO (1975) Spatial scales of current speed and phytoplankton biomass fluctuations in Lake Tahoe. Science 189:1088-1089

Raby D, Lagadeuc Y, Dodson JJ, Mingelbier M (1994) Relationship between feeding and vertical distribution of bivalve larvae and mixed waters. Mar Ecol Prog Ser 130: 275-284

Raimbault P, Gentilhomme V (1990) Short- and long-term responses of the marine diatom Phaeodactylum tricornutum to spike additions of nitrate at nanomolar levels. J Exp Mar Biol Ecol 135:161-176

Riebesell U (1991a) Particle aggregation during a diatom bloom. I. Physical aspects. Mar Ecol Prog Ser 69:273-280

Riebesell U (1991b) Particle aggregation during a diatom bloom. II. Biological aspects. Mar Ecol Prog Ser 69:281-291

Sakamoto CM, Friederich GE, Service SK, Chavez FP (1996) Development of automated surface seawater nitrate mapping systems for use in open ocean and coastal waters. Deep-Sea Res Part I 43:1763-1775

Schroeder M (1991) Fractals, chaos, power laws. WH Freeman, New York

Seuront L, Lagadeuc Y (1997) Characterisation of space-time variability in stratified and mixed coastal waters (Baie des Chaleurs, Québec, Canada): application of fractal theory. Mar Ecol Prog Ser 159:81-95

Seuront L, Lagadeuc Y (1998) Spatio-temporal structure of tidally mixed coastal waters: variability and heterogeneity. J Plankton Res 20:1387-1401

Seuront L, Schmitt F, Schertzer D, Lagadeuc Y, Lovejoy S (1996a) Multifractal intermittency of Eulerian and Lagrangian turbulence of ocean temperature and plankton fields. Nonlinear Proc Geophys 3:236-246

Seuront L, Schmitt F, Lagadeuc Y, Schertzer D, Lovejoy S, Frontier S (1996b) Multifractal analysis of phytoplankton biomass and temperature in the ocean. Geophys Res Lett 23:3591-3594

Seuront L, Schmitt F, Lagadeuc Y, Schertzer D, Lovejoy S (1999) Universal multifractal analysis as a tool to characterize multiscale intermittent patterns: example of phytoplankton distribution in turbulent coastal waters. J Plankton Res 21:877-922

Siegel S, Castellan NJ (1988) Nonparametric stsistics. McGraw-Hill, New York

Steele JH, Henderson EW (1979) Spatial patterns in North Sea plankton. Deep-Sea Res 26:955-963

Strickland JDH, Parsons TR (1972) A practical handbook of seawater analysis. Bull Fish Res Board Can 167:1-311

Sugihara G, May RM (1990) Applications of fractals in ecology. TREE 5:79-86

Taylor GI (1938) The spectrum of turbulence. Proc R Soc Lond Ser A 20:1167-1170 
Treguer P, Le Corre P (1971) Manuel d'analyse des sels nutritifs dans l'eau de mer (utilisation de l'autoanalyseur II Technicon). Université de Bretagne Occidentale

Truffier S, Hitier B, Olivesi R, Delesmont R, Morel M, Loquet N (1997) Suivi regional des nutriments sur le littoral Nord/ Pas-de-Calais/Picardie. Rapport IFREMER, Boulogne/Mer

Tyler PJ (1977) Microbiological and chemical studies of Phaeocystis. PhD thesis, University of Wales

Editorial responsibility: Otto Kinne (Editor),

Oldendorf/Luhe, Germany
Weber LH, El-Sayed SZ, Hampton I (1986) The variance spectra of phytoplankton, krill and water temperature in the Antarctic Ocean south of Africa. Deep-Sea Res 33:1327-1343

Wilcox Silver M, Shanks AL, Trent JD (1978) Marine snow: microplankton habitat and source of small-scale patchiness in pelagic populations. Science 201:371-373

Zar JH (1984) Biostatistical analysis. Prentice-Hall, Englewood Cliffs, NJ

Submitted: February 28, 2000; Accepted: July 10, 2001

Proofs received from author(s): April 11, 2002 